\title{
Results of the implementation of the code stroke protocol in a Portuguese hospital
}

Resultados da implementaçáo do protocolo da via verde do acidente vascular cerebral num hospital português

Resultados de la implementación del protocolo código ictus en un hospital portugués

Ilda Maria Morais Barreira*iD; Matilde Delmina Martins**iD; Norberto Pires Silva***iD;

Pedro Miguel Barreira Preto**** (iD) Leonel São Romão Preto***** (iD

\begin{abstract}
Background: The latest therapies for stroke are time-sensitive and require the implementation of care protocols.

Objective: To analyze the results of the implementation of a code stroke protocol.

Methodology: Quantitative and retrospective analysis of all cases with cerebrovascular disease admitted in the emergency room of a Portuguese hospital, from 2010 to $2016(n=1200)$. Demographic data, times for stroke care, comorbidities, and other clinical variables were collected. All activations of the protocol were studied using electronic records.

Results: The patients showed $63.0 \%$ ischemic stroke, $17.2 \%$ of hemorrhagic stroke, and $19.8 \%$ of transient ischemic attacks. The code stroke protocol covered $37.3 \%(n=282)$ of the ischemic stroke cases, performing fibrinolysis in $18.4 \%(n=52)$ of these patients. The mean door-to-needle time was 69.5 minutes. In patients who underwent fibrinolysis, neurological improvements were significant $(p<0.05)$.

Conclusion: There was a high rate of activation of the code stroke protocol, but only 52 patients underwent fibrinolysis. Age, comorbidities, and high rate of rural origin of patients may have influenced the therapeutic window and the inclusion/ exclusion criteria for fibrinolysis.
\end{abstract}

Keywords: cerebral vascular accident; emergency room, hospital; fibrinolysis; code stroke

\section{Resumo}

Enquadramento: No acidente vascular cerebral (AVC), as terapêuticas recentes são tempo-dependentes e requerem a implementação de protocolos de atendimento.

Objetivo: Analisar os resultados da implementaçáo de um protocolo de Via Verde (VV) do AVC.

Metodologia: Análise quantitativa e retrospetiva de todos os casos com doença cerebrovascular admitidos num serviço de urgência de um hospital português, desde 2010 a $2016(n=1200)$. Foram recolhidos dados sociodemográficos, tempos assistenciais, comorbilidades e outras variáveis clínicas. Através dos registos eletrónicos, estudaram-se todas as ativaçóes do protocolo.

Resultados: Os doentes apresentavam: 63,0\% AVC isquémico, 17,2\% AVC hemorrágico e 19,8\% acidente isquémico transitório. A VV cobriu 37,3\% $(n=282)$ dos casos de AVC isquémico, realizando fibrinólise 18,4\% (n $=52$ ) desses doentes. O tempo médio porta-agulha foi de 69,5 minutos. Nos doentes fibrinolisados registaram-se melhorias neurológicas significativas $(p<0,05)$.

Conclusáo: Obteve-se uma taxa elevada de ativação da VV, mas apenas 52 doentes realizaram fibrinólise. A idade, a comorbilidade, e a elevada procedência rural dos pacientes poderão ter influenciado a janela terapêutica e os critérios de inclusão/exclusão para fibrinólise.

Palavras-chave: acidente vascular cerebral; serviço hospitalar de emergência; fibrinólise; via verde do acidente vascular cerebral

*MSc., RN, Local Health Unit of Nordeste, EPE, Emergency Room, 5301-852, Bragança, Portugal [ildabarreira25@gmail.com]. (1) https://orcid.org/0000-0002-1788-6018. Contribution to the article: data collection, bibliographical research, writing of the article.

**Ph.D., Adjunct Professor, Polvtechnic Institute of Braganca, School of Health, 5300-146, Bragança, Portugal [matildemartins@ipb.pt].D https://orcid.org/0000-0003-2656-5897.Contribution to the article: research project, overall article revision.

tribution to the article: research project, overall article revision. *.* MSc., Specialist Nurse, Local Health Unit of Nordeste, EPE, Emergency Room, 5301-852,
Bragança, Portugal [norbertosilva@sapo.pt]. (1) https://orcid.org/0000-0002-0689-1567.Contribution to the article: research project, guidance of field work.

****BSc., RN, Local Health Unit of Nordeste, EPE, Trauma Unit, 5301-852, Bragança, Portugal [pedrobarreirapreto@hotmail.com]. (D) https://orcid.org/0000-0002-6488-4533. Contribution to the article: statistical treatment and assessment.

****:Ph.D., Coordinating Professor, Polytechnic Institute of Bragança, School of Health, 5300-146, Bragança, Portugal [leonelpreto@ipb.pt]. (1) http://orcid.org/0000-0002-81267051. Contribution to the article: writing of the article. Address for correspondence: Rua Senhor dos Perdidos nº101, 5301-392, Bragança, Portugal.

\section{Resumen}

Marco contextual: En el accidente cerebrovascular (ACV), las terapias recientes dependen del tiempo y requieren la implementación de protocolos de atención. Objetivo: Analizar los resultados de la implementación de un protocolo código ictus de ACV.

Metodología: Análisis cuantitativo y retrospectivo de todos los casos de enfermedad cerebrovascular ingresados en un servicio de urgencias de un hospital portugués entre 2010 y $2016(n=1200)$. Se recogieron datos sociodemográficos, tiempos de atención, comorbilidades y otras variables clínicas. Todas las activaciones del protocolo se estudiaron a través de registros electrónicos.

Resultados: El 63,0\% de los pacientes presentó ACV isquémico, el 17,2\% ACV hemorrágico y el 19,8\% accidente isquémico transitorio. El protocolo código ictus cubrió el 37,3\% $(n=282)$ de los casos de ACV isquémico, y se realizó fibrinólisis en el 18,4\% $(n=52)$ de estos pacientes. El tiempo medio de puerta-aguja fue de 69,5 minutos. Se registraron mejoras neurológicas significativas $(p<0,05)$ en pacientes en fibrinólisis.

Conclusión: Se obtuvo una elevada tasa de activación del protocolo código ictus, pero solo 52 pacientes se sometieron a fibrinólisis. La edad, la comorbilidad y la elevada procedencia rural de los pacientes pueden haber influido en la ventana terapéutica y en los criterios de inclusión/exclusión para la fibrinólisis.

Palabras clave: accidente cerebrovascular; servicio de urgencia en hospital; fibrinólisis; código ictus

Received for publication: 27.11 .18

Accepted for publication: 05.03.19

Série IV - n. ${ }^{\circ} 22$ - JUL./AGO./SET 2019 


\section{Introduction}

Stroke, or cerebrovascular accident (CVA), is a significant cause of death and disability across the world.

Based on the knowledge on cerebrovascular diseases (CVD), current recommendations highlight the control of cardiovascular risk factors (CVRF), the understanding of warning signs, the increase of stroke units, the reinforcement of the training of health professionals, and the implementation of emergency protocols in the pre- and intra-hospital stages, usually designated as code stroke (Jauch et al., 2013).

The main objective of the code stroke protocol is that all ischemic stroke victims arrive at a hospital in time and have quick access to a definitive diagnosis and, in eligible cases, to reperfusion treatment (Jauch et al., 2013).

The pharmacological reperfusion in ischemic stroke, using intravenous administration of tissue plasminogen activator (IV tPA), reduces mortality and improves functional recovery. Its benefits are well documented in the literature, thus constituting an intervention supported by a grade-A level of evidence (Jauch et al., 2013). Fibrinolysis aims to improve or restore the cerebral blood flow through recanalization and reperfusion of ischemic tissue (Alonso Leciñana et al., 2014). However, the effectiveness of this treatment is time-dependent, as it should not exceed the 4.5-hour therapeutic window after the onset of symptoms, the moment from which the risks outweigh the benefits (Catanese, Tarsia, \& Fisher, 2017).

Many variables can influence the therapeutic window, such as the lack of warning signs of stroke by part of the population, the difficulty in engaging the emergency services, the poor accessibility to health services, or the hustle of the intra-hospital procedures (Jauch et al., 2013).

In this last aspect, it is recommended that patients who undergo intravenous fibrinolysis do it with mean door-to-needle times below 60 minutes (Alonso Leciñana et al., 2014). In this way, a medical-surgical emergency room (ER) should implement the code stroke according to the national and international recommendations, organizing efficient ways to receive, evaluate, diagnose, treat, or transfer patients with stroke. In Portugal, the code stroke pro- gram was implemented in 2005, to reduce stroke-related mortality, which represented 97.6 per 100000 inhabitants, with significant regional variations (Silva \& Gouveia, 2012).

A research overview was designed considering the above mentioned clinical and organizational issues, to analyze the results of the implementation of the code stroke protocol in the ER of a hospital in northern Portugal from 2010 to 2016. This general objective was met, following these specific objectives: i) to characterize the sample in the sociodemographic variables; (ii) to determine the percentage of ischemic stroke, hemorrhagic stroke, and transient ischemic attack (TIA); (iii) to evaluate the prevalence of CVRF; iv) to calculate the rate of activation of the code stroke protocol and the results of fibrinolysis; v) to evaluate the times for stroke care (door-to-doctor, door-to-examination, and door-to-needle).

\section{Background}

Stroke is a medical emergency that requires immediate treatment. In recent years, there have been significant changes in the therapeutic approach of CVD, particularly in ischemic stroke. New treatments of recanalization (intravenous fibrinolysis, intra-arterial thrombolysis, and endovascular thrombectomy) emerged for neurological recovery and improvement in the quality of life (Jauch et al., 2013).

However, these treatments are effective in a very short period, and it was necessary to adapt the health services to the new paradigm Time is Brain (Alonso Leciñana et al., 2014).

This adaptation was made using the code stroke protocol, which can be activated in the pre- or intra-hospital stages.

During the triage of the person with a suspected stroke, the importance of the role of the nurse is all too evident. It depends on the strict, quick, and efficient activation of the intra-hospital code stroke protocol, provided that the patient presents at least one of the classic focal signs of the Cincinnati Scale (arm drift, facial droop, and slurred speech; Jauch et al., 2013; Pereira, Guedes, Oliveira, \& Martins, 2017).

The identification of the signs of the Cincinnati Scale was the first stage of the decision-making process, followed by the evaluation of the 
following inclusion criteria: age above 18 years old; symptom onset for less than 4.5 hours; and absence of prior dependence. In the event of the activation of the code stroke, the triage nurse should contact the neurologist so that the code stroke care protocol can begin. Thus, the identification of the Cincinnati symptoms and the activation of the code stroke are fundamental and time-sensitive steps in the chain of treatment of acute stroke.

After the activation of the code stroke, the patient should be observed in the neurology unit (or in Internal Medicine, in the case there is no neurology) within the first 10 minutes after contact made by the triage nurse. The initial medical evaluation includes the general physical examination, collecting the clinical background, and the neurological exam, with the application of the respective scales (Glasgow Coma Scale and National Institutes of Health Stroke Scale - NIHSS; Jauch et al., 2013). If the initial medical examination does not confirm the suspicion of ischemic stroke, the code stroke is deactivated. If the suspicion is validated, the time of onset of symptoms is recorded, analytical tests of the protocol are conducted, a 12-lead electrocardiogram (ECG) is performed, and the radiology service is contacted to execute the brain computed tomography (CT; Direção-Geral da Saúde, 2017). The door-to-CT scan report time should not exceed 45 minutes (Jauch et al., 2013). The CT scan report is, therefore, urgent and mandatory, since it is essential for the establishment of a diagnosis and contributes to the screening of candidates to fibrinolysis, excluding the existence of hemorrhage. Given its risk-benefit ratio, performing fibrinolysis is a clinical decision, which should meet the inclusion and exclusion criteria described in the international guidelines (Jauch et al., 2013; Powers et al., 2018).

The nurse has a fundamental role in the administration of fibrinolytic therapy and its continuous surveillance and monitoring to prevent complications (Cavalcante et al., 2011).

The fibrinolysis with tPA IV administration is associated with improved long-term survival and functional status after ischemic stroke. A recently published study shows that, on average, and for 10 years, a patient with thrombosis lives about 1 year more than a similar patient with no thrombosis (Muruet, Rudd, Wolfe,
$\&$ Douiri, 2018). The same study refers to the association between fibrinolysis and functional independence, as measured by the Barthel Index, for five years (Muruet et al., 2018).

In Portugal, studies on the evaluation of the stroke care chain in the ER are scarce. Pereira et al. (2017) conducted a study that analyzed data from ALERT ${ }^{\circ}$ software about 864 stroke patients admitted to an ER; however, its analysis focused more on the Manchester Triage System, on the flowcharts, and the outcomes. Nevertheless, the authors report a $14 \%$ rate of activation of the code stroke, which they classify as low and justify with the lack of records. Another study conducted in northern Portugal, with a sample of 600 stroke patients, found 48 cases of extra-hospital code stroke activation and 50 cases of intra-hospital code stroke activation, which represents a $16.3 \%$ rate of overall activation. The same study also concluded that the time elapsed between the onset of first symptoms and the arrival at the ER was, on average, 82 minutes (Moutinho, Magalhães, Correia, \& Silva, 2013).

In other countries, the casuistry on the code stroke is better documented. Taking Spain as an example, a study carried out in the province of Cáceres found an activation rate of $31 \%$, with fibrinolytic treatment administered to $10.2 \%$ of all patients with ischemic stroke (Espuela, Gracia, Barriga, \& Gutiérrez, 2010). Another study performed in a hospital in the province of Castellón found code stroke activation rates of $37.9 \%$, with fibrinolysis rates of $12.7 \%$ and door-to-needle time of 59.7 minutes (Geffner-Sclarsky et al., 2011).

\section{Research Question}

Are patients with acute ischemic stroke, to whom the code stroke was activated, treated with times for stroke care (door-to-doctor, door-to-analysis, and door-to-needle) according to international guidelines?

\section{Methodology}

An observational, retrospective study was conducted to meet the proposed objectives.

The study was carried out in a medical-sur- 
gical ER of a hospital in northern Portugal, which serves a resident population of 136,252 inhabitants, spread over a geographical area of $6608 \mathrm{~km}^{2}$.

The sample was composed of all the cases of acute cerebrovascular disease admitted consecutively to the ER from 1 January 2010 until 31 December 2016. Patients who were admitted to the service with stroke in progress for more than 24 hours were excluded from the research. The data collection process began with requesting to the IT department a list of all patients coded with the diagnosis of ischemic stroke, hemorrhagic stroke, and TIA in the period under analysis. Then, the study variables were assessed using electronic records, considering only the information relating to the first 24 hours of hospitalization. Data collection omitted the identification of patients and was based on a structured document which contained sociodemographic, clinical, and context variables. The variables studied are included in the guidelines for the early treatment of acute ischemic stroke (Jauch et al., 2013) and were also analyzed in studies with similar objectives to those of this study (Chen et al., 2014; Dalloz et al., 2012; Espuela et al., 2010). The data collection process was supervised by the service's management and by nursing professionals with triage experience and knowledge of the established protocols, aiming to minimize errors. About the sociodemographic variables, there was gender, age, and origin of the patients.

About clinical variables, the activation of the code stroke was carried out in a yes/no dichotomy and relates to the activation of the protocol by the triage nurse or by the services of pre-hospital emergency care. Still, regarding the clinical variables, the values glycemia, heart rate, and blood pressure in the first ER evaluation were considered. The CVRF and mortality within the first 24 hours were analyzed. Patients with ischemic stroke underwent fibrinolysis, and others did not, with written justification. The severity of symptoms before and after fibrinolysis was assessed using the scores obtained in the NIHSS scale before and two hours after the treatment. The NIHSS is a tool widely used in neurological care and constitutes the primary standard for evaluating and classifying the severity of a stroke (Lyden, 2017). The scale ranges from a minimum of
0 points to a maximum value of 42 . In the service where this study was developed, and according to international recommendations, the inclusion criterion is thrombolysis patients who present between five and 25 points on the scale (Demaerschalk et al., 2016).

About the contextual variables, the patient's arrival time to the ER, the time of the first clinical evaluation, the time of execution of laboratory examinations, and the time of completion of the fibrinolysis (in cases in which this treatment was carried out) were researched. Thus, it was possible to determine the door-to-doctor, door-to-examination, and door-to-needle times. Because of a lack of consistent and systematized information, it was impossible to evaluate the door-to-TAC report time.

This study obtained a favorable opinion of the Ethics Committee, with registration number 006542. Anonymity, privacy, and confidentiality of information collected were respected. Because of its retrospective nature, this study had no impact on the organization of care, treatments, or physical integrity of patients.

After data collection, the information was entered on a database created in the IBM SPSS Statistics software, version 23.0. Procedures of descriptive and inferential analysis were used. For the quantitative variables, the mean and standard deviation were measured, using the $t$-test for independent samples and the ANOVA test. The relation between qualitative variables was assessed by the Chi-squared test. In all tests, the results were analyzed for a confidence interval of $95 \%(p<0.05)$.

\section{Results}

Table 1 summarizes the results obtained for the sociodemographic variables. Thus, from January 2010 to December 2016, 1200 patients with CVD were admitted to the ER and diagnosed with ischemic stroke $(n=756 ; 63.0 \%)$, hemorrhagic stroke $(n=207 ; 17.2 \%)$, and TIA $(n=237 ; 19.8 \%)$.

The mean age was 77.4 years ( \pm 11.2 years) for the total sample, patients with ischemic stroke being older $(p<0.001)$. In the distribution by gender, men are predominant, regardless of the type of CVD. The patients lived mostly in rural areas. 
Table 1

Sociodemographic characteristics of patients

\begin{tabular}{|c|c|c|c|c|c|}
\hline & $\begin{array}{l}\text { Patients } \\
(n=1200)\end{array}$ & $\begin{array}{c}\text { Ischemic stroke } \\
\quad(n=756)\end{array}$ & $\begin{array}{c}\text { Hemorrhagic } \\
\text { stroke }(n=207)\end{array}$ & $\begin{array}{c}\text { TIA } \\
(n=237)\end{array}$ & $p$ \\
\hline Age in years ${ }^{b}$ & $77.4 \pm 11.2$ & $78.6 \pm 10.7$ & $76.1 \pm 11.9$ & $74.9 \pm 11.5$ & $<0.001^{\mathrm{a}}$ \\
\hline \multicolumn{6}{|l|}{ Gender, $n(\%)$} \\
\hline Female & $542(45.2 \%)$ & $348(46.0 \%)$ & $92(44.4 \%)$ & $102(43.0 \%)$ & $0.703^{\mathrm{c}}$ \\
\hline Male & $658(54.8 \%)$ & $408(54.0 \%)$ & $115(55.6 \%)$ & $135(57.0 \%)$ & \\
\hline \multicolumn{6}{|l|}{ Origin, $n(\%)$} \\
\hline Rural & $962(80.2 \%)$ & $599(79.2 \%)$ & $167(80.7 \%)$ & $196(82.7 \%)$ & $0.495^{\mathrm{c}}$ \\
\hline Urban & $238(19.8 \%)$ & $157(20.8 \%)$ & $40(19.3 \%)$ & $41(17.3 \%)$ & \\
\hline
\end{tabular}

Note. TIA = transient ischemic attack; ${ }^{\mathrm{a} A N O V A}$ test; ${ }^{\mathrm{b}}$ mean \pm standard deviation; ${ }^{\mathrm{c}}$ Chi-squared test.

Table 2 shows information on the CVRF and other clinical variables, for the total sample and disintegrated by type of CVD.

The most prevalent CVRF was hypertension (HT), especially in patients with stroke $(66.7 \%$; $p=0.036)$. The second most found risk factor was dyslipidemia (30.3\%). The third was the background of diabetes mellitus (DM), a condition that amounted to $26.5 \%$ of the participants. About atrial fibrillation (AF), this CVRF was more frequent in patients with ischemic stroke $(25.4 \% ; p=0.042)$.
The patients with hemorrhagic stroke showed significantly higher values of systolic blood pressure (SBP), diastolic blood pressure (DBP), and glycemia, with statistical significance $(p<$ $0.05)$. Concerning the peripheral oxygen saturation $\left(\mathrm{SpO}_{2}\right)$, this group of patients obtained the worst results $(94.9 \pm 4.3 \%)$.

Early mortality (first 24 hours) included 29 cases of the total sample, reaching $0.9 \%$ in ischemic stroke and $10.6 \%$ in the hemorrhagic stroke. As it turns out, there were no deaths by TIA.

Table 2

Background and clinical variables

\begin{tabular}{lccccc}
\hline & $\begin{array}{c}\text { Patients } \\
(n=1200)\end{array}$ & $\begin{array}{c}\text { Ischemic stroke } \\
(n=756)\end{array}$ & $\begin{array}{c}\text { Hemorrhagic stroke } \\
(n=207)\end{array}$ & $\begin{array}{c}\text { TIA } \\
(n=237)\end{array}$ & $p^{\mathrm{a}}$ \\
\hline Background, $n(\%)$ & & & & & \\
HT & $776(64.7 \%)$ & $504(66.7 \%)$ & $118(57.0 \%)$ & $154(65.0 \%)$ & 0.036 \\
DM & $318(26.5 \%)$ & $200(26.5 \%)$ & $53(25.6 \%)$ & $65(27.4 \%)$ & 0.909 \\
IHD & $71(5.9 \%)$ & $42(5.6 \%)$ & $12(5.8 \%)$ & $17(7.2 \%)$ & 0.652 \\
AF & $279(23.3 \%)$ & $192(25.4 \%)$ & $36(17.4 \%)$ & $51(21.5 \%)$ & 0.042 \\
Dyslipidemia & $363(30.3 \%)$ & $232(30.7 \%)$ & $49(23.7 \%)$ & $82(34.6 \%)$ & 0.040 \\
Obesity & $155(12.9 \%)$ & $86(11.4 \%)$ & $32(15.5 \%)$ & $37(15.6 \%)$ & 0.116 \\
Prior CVD & $193(16.1 \%)$ & $128(16.9 \%)$ & $34(16.4 \%)$ & $31(13.1)$ & 0.367 \\
Smoking & $75(6.3 \%)$ & $39(5.2 \%)$ & $19(9.2 \%)$ & $17(7.2 \%)$ & 0.086 \\
\hline
\end{tabular}




\begin{tabular}{|c|c|c|c|c|c|}
\hline \multicolumn{6}{|l|}{ Blood pressure ${ }^{b}$} \\
\hline SBP (mmHg) & $151.0 \pm 30.3$ & $149.5 \pm 29.3$ & $160.4 \pm 35.7$ & $147.5 \pm 26.2$ & $<0.001$ \\
\hline $\mathrm{DBP}(\mathrm{mmHg})$ & $79.7 \pm 17.0$ & $79.1 \pm 16.4$ & $84.2 \pm 20.3$ & $77.5 \pm 14.6$ & $<0.001$ \\
\hline \multicolumn{6}{|l|}{ Other clinical variables ${ }^{a}$} \\
\hline HR (ppm) & $77.3 \pm 16.9$ & $77.8 \pm 16.9$ & $77.9 \pm 18.6$ & $75.2 \pm 15.0$ & 0.107 \\
\hline $\mathrm{SpO}_{2}(\%)$ & $95.6 \pm 3.3$ & $95.6 \pm 3.2$ & $94.9 \pm 4.3$ & $96.3 \pm 2.4$ & $<0.001$ \\
\hline Glycaemia (mg/dL) & $143.8 \pm 65.3$ & $144.8 \pm 64.9$ & $155.7 \pm 78.6$ & $130.0 \pm 50.1$ & 0.002 \\
\hline $\begin{array}{l}\text { Clinical discharge } \\
\text { within } 24 \text { hours, } \\
n(\%)\end{array}$ & $78(6.5 \%)$ & $21(2.8 \%)$ & $4(1.9 \%)$ & $53(22.4 \%)$ & - \\
\hline $\begin{array}{l}\text { Mortality within } 24 \\
\text { hours, } n(\%)\end{array}$ & $29(2.4 \%)$ & $7(0.9 \%)$ & $22(10.6 \%)$ & $0(0.0 \%)$ & - \\
\hline
\end{tabular}

Note. TIA = transient ischemic accident HT = hypertension; $\mathrm{DM}=$ diabetes mellitus; $\mathrm{IHD}=$ ischemic heart disease; $\mathrm{AF}=$ atrial fibrillation; $\mathrm{CVD}=$ cerebrovascular disease; $\mathrm{SBP}=$ systolic blood pressure; $\mathrm{DBP}=$ diastolic blood pressure; $\mathrm{HR}$ = heart rate; $\mathrm{SpO}_{2}$ : peripheral oxygen saturation; ${ }^{\mathrm{a}} \mathrm{By}$ means of the chi-squared and ANOVA test; ${ }^{\mathrm{b}}$ mean \pm standard deviation.

Table 3 presents the results of the code stroke, the number of performed fibrinolyses, and baseline and post-treatment scores obtained in the NIHSS. As it is noted, the code stroke was activated in 431 cases and covered $37.3 \%$ of all ischemic stroke.

When activating the code stroke $(n=431)$, the patients were clinically evaluated with door-todoctor times of $9.9 \pm 3.2$ minutes.

Of the 282 patients with ischemic stroke who initiated the code stroke protocol, 52 (18.4\%) cases eventually perform fibrinolytic treatment, which corresponds to a fibrinolysis rate of $6.9 \%$ for ischemic stroke $(n=756)$. Patients who underwent fibrinolysis did with door-to-examination times of $38.3 \pm 11.7$ minutes and door-to-needle times of $69.5 \pm 13.1$ minutes. A significant neurological improvement $(p<$ 0.001 ) was observed, using the NIHSS before and two hours after the treatment. As it was observed, three cases had hemorrhagic transformation.

Table 3

Activations of the code stroke and performed fibrinolyses

\begin{tabular}{|c|c|c|c|c|c|}
\hline & $\begin{array}{l}\text { Patients } \\
(n=1200)\end{array}$ & $\begin{array}{c}\text { Ischemic stroke } \\
\quad(n=756)\end{array}$ & $\begin{array}{c}\text { Hemorrhagic } \\
\text { stroke }(n=207)\end{array}$ & $\begin{array}{c}\text { TIA } \\
(n=237)\end{array}$ & $p$ \\
\hline Code stroke activation, $\mathrm{n}(\%)$ & $\begin{array}{c}431 \\
(35.9 \%)\end{array}$ & $282(37.3 \%)$ & $57(27.5 \%)$ & $92(38.8 \%)$ & $0.020^{\mathrm{a}}$ \\
\hline Door-to-doctor $(n=431)$ & $9.9 \pm 3.2$ & $10.0 \pm 3.4$ & $9.4 \pm 3.0$ & $9.9 \pm 2.5$ & $0.355^{\mathrm{b}}$ \\
\hline Fibrinolysis, $n(\%)$ & - & $\begin{array}{c}52\left(18.4 \%^{\mathrm{c}} v\right. \\
\left.6.9 \%{ }^{\mathrm{c}}\right)\end{array}$ & - & - & - \\
\hline Door-to-examination (min) & - & $38.3 \pm 11.7$ & & & \\
\hline Door-to-needle (min) & - & $69.5 \pm 13.1$ & - & - & - \\
\hline
\end{tabular}


NIHSS - pre-fibrinolysis

$14.8 \pm 5.2$

NIHSS - 2 hours post-fibrinolysis

$11.8 \pm 5.9$

$3\left(5.8 \%{ }^{\mathrm{e}}\right)$

Hemorrhagic transformation, $n(\%)^{\mathrm{e}}$ $<0.001^{\mathrm{d}}$

Note. TIA = transient ischemic accident; NIHSS = National Institutes of Health Stroke Scale; ${ }^{a}$ By means of the Chi-squares test; ${ }^{\mathrm{b}} \mathrm{ANOVA}$ test; ${ }^{\mathrm{c} C a l c u l a t e d ~ p e r c e n t a g e s, ~ t a k i n g ~ i n t o ~ a c c o u n t ~ t h e ~ p a t i e n t s ~ w i t h ~ i s c h e m i c ~ s t r o k e ~ w h o ~}$

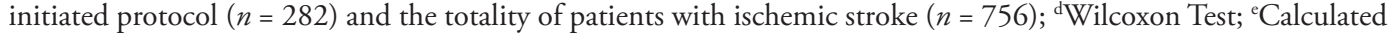
percentage, taking into account the patients who underwent fibrinolysis $(n=52)$.

For greater understanding, the following figure shows the flowchart of patients who initiated the code stroke. As it turns out, after activation of the code stroke in the triage, the protocol was later deactivated after the diagnosis of hemorrhages or TIA. In cases of ischemic stroke, which followed protocol $(n=282)$, the vast majority were not considered eligible for fibrinolysis $(n=230)$. Although the non-eligibility is mainly due to the clinical exclusion criteria contained in the protocol $(n=177)$, there were 33 cases which exceeded the time of the 4.5-hour therapeutic window after the onset of symptoms. It should be noted that, of the patients who underwent fibrinolysis $(n=52)$, three cases carried on the inter-hospital code stroke protocol, having been transferred to a central hospital in order to perform thrombectomy.

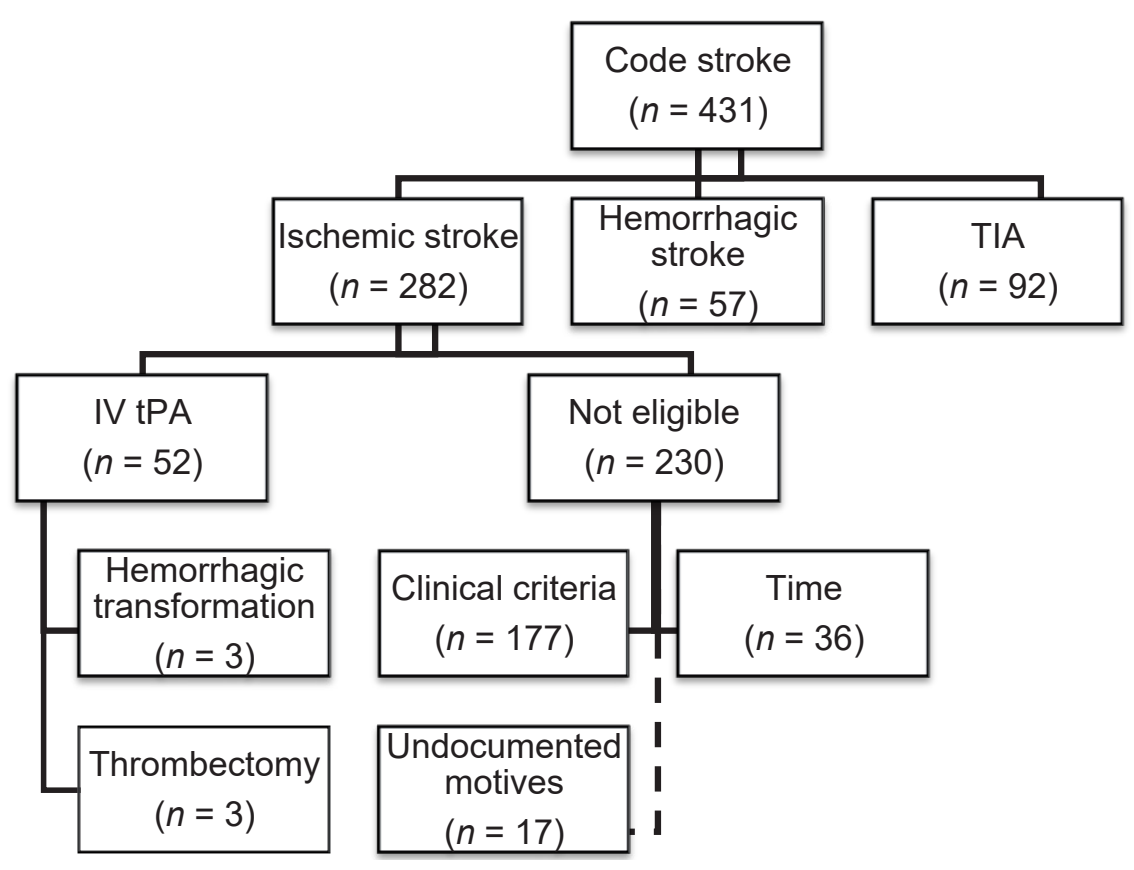

Figure 1. Diagram of activation of the code stroke and distribution of patients. 


\section{Discussion}

One of the goals of this study was to characterize the sample within the sociodemographic variables. The analysis of the age variable reveals an aging population, reflecting the demographic reality of the geographical context of the study (district of Bragança). It is known that age is an independent risk factor for stroke. The risk increases significantly from 55 years of age on, and the incidence rate multiplies by ten after the 75 years of age (Díaz-Guzmán et al., 2009). The majority of patients lived in a rural environment. People living in rural areas may struggle more to have access to differentiated care, and this variable may reflect on health outcomes. A recent study concluded that patients with ischemic stroke residing in rural areas are less likely to access the fibrinolysis within the therapeutic window, in comparison with patients residing in urban environments (Gonzales, Mullen, Skolarus, Thibault, \& Udoeyo, 2017). On the other hand, it is known that, in Portugal, the incidence of stroke is higher in rural areas of the northern countryside (Correia et al., 2017).

Another objective of this study was to determine the percentage of ischemic stroke, hemorrhagic stroke, and TIA during the period under analysis. The results are in line with epidemiological surveys that indicate that the ischemic stroke is more prevalent than the hemorrhagic stroke (Correia et al., 2017).

Atrial fibrillation (AF) has presented, in this study, a higher prevalence in ischemic strokes. These data relate to thematic literature that refers that AF is at the origin of nearly $50 \%$ of cardioembolic ischemic strokes (Jauch et al., 2013). In the acute phase, AF should be early detected using the ECG, and the monitoring of the patient within the first 24 hours aims primarily to trace arrhythmias, including AF (Powers et al., 2018).

This study obtained a $35.9 \%$ rate of activation of the code stroke protocol for ischemic stroke. The review of thematic literature found rates of activation of the protocol which vary between 31\%-38\% in Spain (Espuela et al., 2010; Geffner-Sclarsky et al., 2011) and around 35\% in France (Dalloz et al., 2012).

Despite the high rate of activation of the code stroke protocol, only 52 cases of ischemic stroke underwent fibrinolysis. Factors such as age, presence of comorbidities, and initial stroke severity affect the rate of fibrinolysis (Alonso Leciñana et al., 2014; Jauch et al., 2013). It is considered that these and other variables may have influenced the rates of fibrinolytic treatment in this study. A considerable percentage of patients with ischemic stroke had prior CVD, a condition which frequently coexists with functional dependence, thus excluding the fibrinolytic treatment. Also, the rural origin of patients may have influenced the 4.5-hour therapeutic window.

The door-to-needle time found $(69.5 \pm 13.1$ min) exceeds the current guidelines, which recommend that there should not be more than 60 minutes between admission and the decision to administer tPA (Jauch et al., 2013; Powers et al., 2018). The reduction of the door-to-needle time increases the rate of fibrinolysis, diminishes complications after treatment and mortality during hospitalization (Jauch et al., 2013). Thus, the efforts to decrease the time of therapeutic window should constitute an ethical imperative of health teams in pre- and intra-hospital settings.

The patients in this study who underwent fibrinolysis went down, on average, three points in the NIHSS. Neurological improvements after the fibrinolytic treatment are well documented in the literature (Alonso Leciñana et al., 2014; Jauch et al., 2013). In the long term, fibrinolysis increases survival rate, functional status, and quality of life (Jauch et al., 2013).

This study presents some limitations that should be considered when interpreting the results. The main one is the fact that there is no data on the pre-hospital care chain and the time elapsed since the activation of the emergency services until the arrival at the hospital. Of the accessed information, it was not possible to obtain systematized records indicating the time of the execution of the CT scan and its report. On the other hand, the information consulted was limited to the time of permanence of patients at the ER, which did not exceed the 24 hours. Finally, the fact that the code stroke has been studied using listings of patients with CVD did not allow assessing the number of activations of the protocol in other situations that mimic the stroke. Despite these limitations, the results of this study may be useful as indicators of 
evaluation of a process in health (code stroke protocol) since its implementation until today. It can lead to plans for the improvement of care and organization.

The mean door-to-needle time exceeded 9.5 minutes more than the international recommendations. Thus, the improvement of times for stroke care should be a goal of the team. Another implication for the practice of care arises from a large number of patients with TIA who were clinically discharged directly from the ER $(n=78)$. This finding should encourage the nursing team for a good preparation for discharge, including training primarily focused on the secondary prevention of new cerebrovascular events.

Finally, the epidemiological data regarding the CVRF found in patients of this study can provide relevant information to other health care professionals, at the three levels of prevention. The intervention on modifiable risk factors, such as the HT, dyslipidemia, and DM, is paramount.

\section{Conclusion}

The code stroke was activated 413 times. Of these patients, 282 were diagnosed with ischemic stroke, which represents a $37.3 \%$ activation rate for this pathology.

A $6.88 \%$ fibrinolysis rate for ischemic stroke was obtained. Of the patients who underwent fibrinolysis $(n=52)$, three were transferred to perform complementary thrombectomy.

About the times for stroke care, fibrinolysis was performed with mean door-to-examination times of 38.3 minutes and door-to-needle times of 69.5 minutes. There was a neurological improvement, two hours after the treatment, with a decrease of three points, on average, in the NIHSS score $(p<0.001)$. Regarding negative treatment outcomes, three cases of hemorrhagic transformation stand out.

Early treatment is crucial for the treatment of acute stroke. There was a high rate of code stroke activation, but only 52 patients underwent fibrinolysis within the therapeutic window. The advanced age of the patients with ischemic pathology, the high presence of comorbidities, and their origin, mostly rural, may have influenced the therapeutic window and the inclusion/exclusion criteria for fibrinolysis. The continuous improvement of prehospital notification processes, the development of telemedicine systems and, above all, the teamwork and good communication are interdisciplinary strategies that may promote the thriving and secure care to patients with stroke. In this respect, nursing professionals are key elements in the implementation of measures leading to the improvement of care. The population of the geographical context of this research should be made aware of the warning signs of stroke and the quick engagement of adequate means of medical assistance, to decrease the time of the therapeutic window. The results of this study point to the need to decrease the doorto-needle time, on average 10 minutes. Clinical records of stroke patients with activation of code stroke should be improved, namely the registration of door-to-CT report time. Given the lack of studies about the chain of stroke care at the national level, the authors suggest further research on this topic.

\section{References}

Alonso Leciñana, M., Egido, J. A., Casado, I., Ribó, M., Dávalos, A., Masjuan, J., ... Vivancos, J. (2014). Guía para el tratamiento del infarto cerebral agudo. Neurología, 29(2), 102-122. doi:10.1016/j. nrl.2011.09.012

Catanese, L., Tarsia, J., \& Fisher, M. (2017). Acute ischemic stroke therapy overview. Circulation Research, 120(3), 541-558. doi:10.1161/CIRCRESAHA.116.309278

Cavalcante, T. F., Moreira, R. P., Guedes, N. G., Araujo, T. L., Lopes, M. V., Damasceno, M. M., \& Lima, F. E. (2011). Intervençôes de enfermagem aos pacientes com acidente vascular encefálico: uma revisão integrativa de literatura. Revista da Escola de Enfermagem da Universidade de São Paulo, 45(6), 1495-1500. doi:10.1590/S0080-62342011000600031

Chen, C. H., Tang, S. C., Tsai, L. K., Hsieh, M. J., Yeh, S. J., Huang, K. Y., \& Jeng, J. S. (2014). Stroke code improves intravenous thrombolysis administration in acute ischemic stroke. PLoS ONE, 9(8). doi:10.1371/ journal.pone.0104862

Correia, M., Magalhães, R., Felgueiras, R., Quintas, C., Guimarães, L., \& Silva, M. (2017). Changes in stroke incidence, outcome, and associated factors in Porto between 1998 and 2011. International Journal of Stroke, 
12(2), 169-179. doi:10.1177/1747493016669846

Dalloz, M. A., Bottin, L., Muresan, I. P., Favrole, P., Foulon, S., Levy, P., ... Alamowitch, S. (2012). Thrombolysis rate and impact of a stroke code: a French hospital experience and a systematic review. Journal of the Neurological Sciences, 314(1-2), 120-125. doi:10.1016/j.jns.2011.10.009

Demaerschalk, B. M., Demchuk, A. M., Fugate, J. E., Grotta, J. C., Khalessi, A. A., Levy, E. I., ... Smith, E. E. (2016). Scientific rationale for the inclusion and exclusion criteria for intravenous alteplase in acute ischemic stroke. Stroke, 47(2), 581-641. doi:10.1161/ STR.0000000000000086

Direção-Geral da Saúde. (2017). Norma No 015/2017: Via verde do acidente vascular cerebral no adulto. Retrieved from https://www.dgs.pt/directrizes-da-dgs/ normas-e-circulares-normativas/norma-n-0152017de-13072017.aspx

Díaz-Guzmán, J., Egido-Herrero, J., Fuentes, B., Fernández-Pérez, C., Gabriel-Sánchez, R., Barberà, G., \& Abilleira, S. (2009). Incidencia de ictus en España: estudio iberictus. Datos del estudio piloto. Revista de Neurología, 48(2), 61-65. doi:10.33588/rn.4802.2008577

Espuela, F., Gracia, M., Barriga, M. I., \& Gutiérrez, J. (2010). Estudio descriptivo de la activación del código ictus en la unidad de ictus de Cáceres. Revista Cientifica de la Sociedad Española de Enfermería Neurológica, 31(1), 22-27. doi:10.1016/S2013-5246(10)70015-5

Geffner-Sclarsky, D., Soriano-Soriano, C., Vilar, C., Vilar-Ventura, R., Belenguer-Benavides, A., Claramonte, B., ... Peinazo-Arias, M. (2011). Código ictus provincial: características e impacto asistencial. Revista de Neurología, 52(8), 457-464. doi:10.33588/rn.5208.2010768

Gonzales, S., Mullen, M., Skolarus, L., Thibault, D., \& Udoeyo, U. (2017). Progressive rural-urban disparity in acute stroke care. Neurology, 88(5), 441-448.
doi:10.1212/WNL.0000000000003562

Jauch, E. C., Saver, J. L., Adams, H. P., Bruno, A., Connors, J. J., Demaerschalk, B. M., ... Yonas, H. (2013). Guidelines for the early management of patients with acute ischemic stroke: a guideline for healthcare professionals from the American Heart Association/ American Stroke Association. Stroke, 44(3), 870-947. doi:10.1161/STR.0b013e318284056a

Lyden, P. (2017). Using the national institutes of health stroke scale. A cautionary tale. Stroke, 48(2), 513-519. doi:10.1161/STROKEAHA.116.015434

Moutinho, M., Magalhães, R., Correia, M., \& Silva, M. C. (2013). A community-based study of stroke code users in northern Portugal. Acta Médica Portuguesa, 26(2), 113-122. doi:10.20344/amp.4103

Muruet, W., Rudd, A., Wolfe, C. D., \& Douiri, A. (2018). Long-term survival after intravenous thrombolysis for ischemic stroke. A propensity score-matched cohort with up to 10-year follow-up. Stroke, 49(3), 607-613. doi:10.1161/STROKEAHA.117.019889

Pereira, M. S., Guedes, H. M., Oliveira, L. M., \& Martins, J. C. (2017). Relação entre o sistema de triagem de Manchester em doentes com AVC e o desfecho final. Revista de Enfermagem Referência, 4(13), 93-102. doi:10.12707/RIV16079

Powers, W. J., Rabinstein, A. A., Ackerson, T., Adeoye, O. M., Bambakidis, N. C., Becker, K., ... Tirschwell, D. L. (2018). 2018 Guidelines for the early management of patients with acute ischemic stroke: a guideline for healthcare professionals from the American Heart Association/American Stroke Association. Stroke, 49(3), e46-e110. doi:10.1161/STR.0000000000000158

Silva, S., \& Gouveia, M. (2012). Program "via verde do AVC": Analysis of the impact on stroke mortality. Revista Portuguesa de Saúde Pública, 30(2), 172-179. doi:10.1016/j.rpsp.2012.12.005 